\title{
Case identification of mental health and related problems in children and young people using the New Zealand Integrated Data Infrastructure
}

Nicholas Bowden ${ }^{1,2^{*}}$ D, Sheree Gibb ${ }^{1,3}$, Hiran Thabrew ${ }^{1,4}$, Jesse Kokaua ${ }^{1,5}$, Richard Audas ${ }^{1,2}$, Sally Merry ${ }^{1,4}$, Barry Taylor ${ }^{1,6}$ and Sarah E Hetrick ${ }^{1,4}$

\begin{abstract}
Background: In a novel endeavour we aimed to develop a clinically relevant case identification method for use in research about the mental health of children and young people in New Zealand using the Integrated Data Infrastructure (IDI). The IDI is a linked individual-level database containing New Zealand government and survey microdata.
\end{abstract}

Methods: We drew on diagnostic and pharmaceutical information contained within five secondary care service use and medication dispensing datasets to identify probable cases of mental health and related problems. A systematic classification and refinement of codes, including restrictions by age, was undertaken to assign cases into 13 different mental health problem categories. This process was carried out by a panel of eight specialists covering a diverse range of mental health disciplines (a clinical psychologist, four child and adolescent psychiatrists and three academic researchers in child and adolescent mental health). The case identification method was applied to the New Zealand youth estimated resident population for the 2014/15 fiscal year.

Results: Over 82,000 unique individuals aged 0-24 with at least one specified mental health or related problem were identified using the case identification method for the 2014/15 fiscal year. The most prevalent mental health problem subgroups were emotional problems (31,266 individuals), substance problems (16,314), and disruptive behaviours $(13,758)$. Overall, the pharmaceutical collection was the largest source of case identification data $(59,862)$.

Conclusion: This study demonstrates the value of utilising IDI data for mental health research. Although the method is yet to be fully validated, it moves beyond incidence rates based on single data sources, and provides directions for future use, including further linkage of data to the IDI.

Keywords: Integrated data infrastructure, Administrative data, Big data, Mental health, Case identification

\section{Background}

Mental health problems are common among children and young people, with a worldwide estimated prevalence of $13.4 \%$ affected by any mental disorder [35]. In New Zealand, school-based survey results indicate 31\% of young people experience at least two weeks of low

\footnotetext{
* Correspondence: Nick.Bowden@otago.ac.nz

${ }^{1}$ A Better Start National Science Challenge, Auckland, New Zealand 2Department of Women's and Children's Health, University of Otago, 201 Great King St, Dunedin 9016, New Zealand

Full list of author information is available at the end of the article
}

mood, $15.7 \%$ report suicidal ideation, and $24 \%$ engage in self-harm each year [14]. The short-term consequences of childhood and adolescent mental health problems can include interference with education [38] and developmental milestones [16]. Longer term, they may be associated with personal costs, such as reduced employment $[12,31]$, poorer quality of life [6], and societal costs such as greater economic burden [39].

Most information regarding the prevalence and treatment of mental health problems originates from small cross-sectional studies with short-term evaluation, and

(c) The Author(s). 2020 Open Access This article is distributed under the terms of the Creative Commons Attribution 4.0 International License (http://creativecommons.org/licenses/by/4.0/), which permits unrestricted use, distribution, and 
occasional, expensive longitudinal studies with finite long-term outcomes. To date, there has been limited use of administrative data for mental health research $[8,19$, 48], especially in children and young people [36]. However, large amounts of administrative data, including information on hospital attendance, community care specialist services, and medication prescriptions, are routinely collected and stored by national health providers and related institutions and may be valuable for health research $[5,17,21]$. Use of data for this purpose is permitted in some countries by privacy legislation [34].

The advantages of using administrative data for research include the large, heterogeneous and representative nature of samples, which allows the reflection of real-world populations and practice, ongoing tracking of problems via regular collection of up-to-date data, long observation periods and low cost. Disadvantages include erroneous interpretation of data beyond the scope for which they were intended, variability of data quality, limited clinical detail, and potential public concern about administrative data being used for research purposes [26]. In New Zealand, administrative data on most interactions with government service providers as well as a range of survey data are housed in Statistics New Zealand's Integrated Data Infrastructure (IDI) [45]. The IDI is readily available, free to use, typically national in scope, and linked at the individual level.

Case identification for physical health problems using administrative data, typically utilising International Classification for Diseases (ICD) coding, has been widespread $[1,10,20,33,37,49,50]$, but less so in mental health [15]. A standardised and accessible case identification approach means research can be more comparable, it negates the need to duplicate work, and permits researchers without specialist mental health knowledge to contribute more easily to the field. There are previous examples where New Zealand administrative mental health data have been used for case identification, but these are typically restricted to a narrow range of diagnoses and are not age specific $[3,23,40]$.

This paper describes the development of an administrative data-based case identification method for research into the mental health of children and young people in New Zealand. The method utilises secondary care service use and medication dispensing data held within the IDI. Given that a large number of individuals with mental health problems are treated in primary care, through alternative therapies, or not at all, the method is not intended to calculate prevalence estimates for mental health problems but can be used to identify a relevant population for which we can examine health trajectories, comorbidities and a range of other wellbeing outcomes. These uses are especially important in understanding the burden of disease for mental health conditions and the impact they have on the lives of children and young people.

\section{Methods}

\section{Integrated Data Infrastructure (IDI)}

The IDI is a large research database managed by Statistics New Zealand, containing a wide range of administrative and survey data $^{1}$ about people and households [45]. Cabinet directives dating back to 1997 mandated Statistics New Zealand to undertake cross-agency data integration and the IDI was established in $2011 .^{2}$ Data in the IDI are held in a secure environment and can be accessed by approved researchers only for projects that are in the public interest. Since 1993 it has been possible to link health datasets together using the National Health Index (NHI) number, however, until the creation of the IDI, it was not possible to routinely combine health and non-health related data. The IDI provides secure access to linked data at an individual level. Data are linked probabilistically by Statistics New Zealand, usually using name, date of birth and sex. ${ }^{3}$ After linking, all identifying information is removed before the data are made available to researchers. The IDI enables more extensive use of government data for research, including supporting the evaluation of the long-term impact of health interventions, with the aim of improved public health [2].

\section{Data privacy}

Statistics New Zealand's 'five safes' framework [44] is used to ensure data privacy is protected. Only approved researchers can use the IDI for projects that have a statistical purpose and are for the public good. All data are de-identified and only accessible via a secure connection from a secure Datalab. Data and results must be aggregated and confidentialised according to Statistics New Zealand protocols [46], and all results are checked by Statistics New Zealand prior to their release from the secure environment.

The legal requirements to protect the IDI data include the Statistics Act 1975, the Privacy Act 1993, and the Tax Administration Act 1994 [44]. In addition to legal requirements a number of Statistics New Zealand

\footnotetext{
${ }^{1}$ For more details on the data contained within the IDI see https:// www.stats.govt.nz/integrated-data/integrated-data-infrastructure\#datain-idi

${ }^{2}$ For more details on the history of the IDI development see http:// archive.stats.govt.nz/browse_for_stats/snapshots-of-nz/integrated-datainfrastructure/idi-how-it-works.aspx\#history

${ }^{3}$ For more details on data linking within the IDI see http://archive. stats.govt.nz/browse_for_stats/snapshots-of-nz/integrated-datainfrastructure/idi-how-it-works.aspx
} 
policies, protocols, and guidelines exist [46]. These include guidelines for information privacy, security, confidentiality policy and data integration, microdata access, and privacy and confidentiality. Regular privacy impact assessments for the IDI also provide a systematic evaluation of the benefits and risks associated with integrating data from a number of sources [47].

\section{Data}

Five datasets are used in this study. All are from administrative sources held within the IDI accessed in June 2019 using the most recent refresh of IDI data at that time. The datasets are each described below, including associated strengths and weaknesses for case identification of mental health and related problems.

\section{Programme for the integration of mental health data (PRIMHD)}

PRIMHD is a national collection of publicly funded specialist mental health service use (PRIMHD activity data) and diagnoses (PRIMHD classification (diagnosis) data). Data are collected from district health boards (DHBs) and non-governmental organisations (NGOs) that provide specialist mental health services and used to report on which services are being provided, and who is providing the services for health consumers across New Zealand's mental health sector [41]. A limitation of PRIMHD data is that it covers only publicly funded specialist mental health care which is targeted to the approximately 3 $\%$ of the population with the most serious mental health problems [27]. It does not cover mental health care provided in a primary care setting (the majority of mental health care in New Zealand), or mental health care provided in the private sector.

\section{PRIMHD classification (diagnosis) data}

PRIMHD classification (diagnosis) data in the IDI were collected from 1 July 2008 to 31 December 2016 and include primary and secondary diagnosis codes (ICD-10AM and Diagnostic and Statistical Manual of Mental Disorders (DSM)-IV). PRIMHD is the only national collection of formal psychiatric diagnoses in New Zealand but it has some limitations. Some people have contact with mental health services but do not have specific diagnoses recorded in PRIMHD. For most (nearly 85\% of these non-specific diagnosis codes), this is because clients were seen for only a brief period and there was insufficient time for a diagnosis to be assigned [29]. This gap in data is reflected in approximately $37 \%$ of all classifications (not clients).

\section{PRIMHD activity data}

PRIMHD activity data in the IDI were collected between 1 July 2008 and 30 June 2018 and contain a range of variables including (i) an activity type code, i.e. a code that classifies the type of healthcare provided, and/or (ii) a team type code, i.e. a code that identifies which team provided a service. These codes can be used to identify individuals with mental health problems. Using PRIMHD activity data, a diagnosis can sometimes be inferred from the type of service the client receives, as with substance use, and can help to improve the coverage and quality of diagnosis information.

\section{The National Minimum Dataset (NMDS)}

NMDS is a national collection of publicly funded New Zealand hospital admissions, including day patients (stays of either 3 hours or more but not overnight) and emergency department visits of greater than 3 hours. Primary and secondary diagnosis codes (ICD-10-AM) are recorded for every hospital event and are used to identify mental health and related problems. NMDS data within the IDI were collected between 1 January 1988 and 31 December 2017. As there have been several changes to NMDS data collection over the years, most notably prior to 1994, for the current study NMDS use is restricted to 1994 onwards [42].

A key advantage of NMDS is the ability to utilise secondary diagnoses, i.e. issues deemed material to an individual's care that are not the main reason for their hospital admission. For example, a patient may be admitted to hospital for a non-mental health reason but their mental health may affect treatment or recovery and is therefore recorded as a secondary diagnosis. In some cases, these individuals will not have accessed services for mental health, or may have done so only in the primary care setting (data not held in the IDI). In these circumstances, NMDS permits case identification of mental health problems not otherwise possible in the IDI.

\section{Socrates}

Socrates is the national database of the Ministry of Health's (MoH's) Disability Support Services clients and service providers. Individuals have data recorded in Socrates when they apply for a needs assessment to access home help or other support services via a Needs Assessment and Service Co-ordination Agency (NASC) throughout New Zealand. A range of disabilities can be recorded on an individual's record and these include some mental health diagnoses. These diagnoses come with the referral for the client; for example from a general practitioner, social worker, treatment and rehabilitation provider, or psychologist. Socrates was established in 2008 and data are robust from 1 January 2010. While Socrates data exist in the 


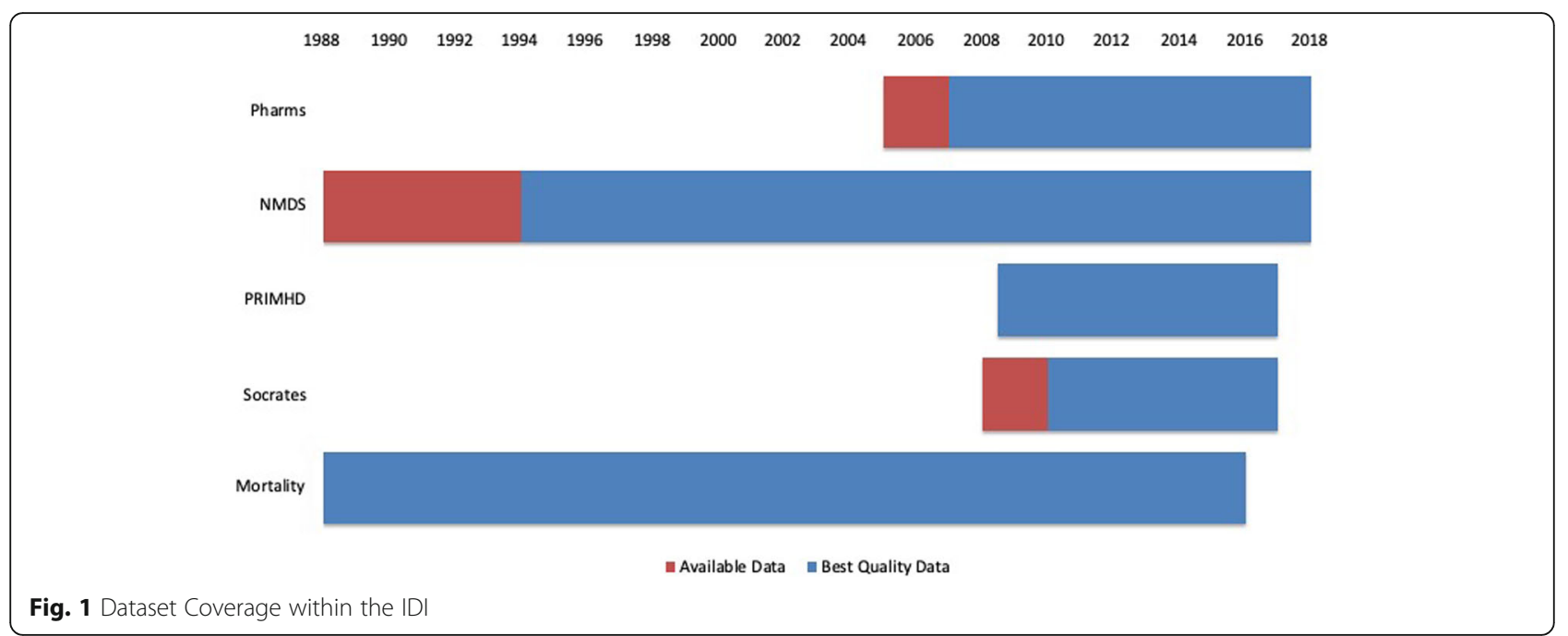

IDI prior to 2008 they are sparse and not deemed reliable.

There is uncertainty around the diagnostic detail in Socrates; it is not known who provides the diagnosis and therefore the accuracy of the diagnosis may vary. However, people with mental health problems, in particular neurodevelopmental disorders such as Attention Deficit and Hyperactivity Disorder (ADHD) can be identified. Some of these children and young people will not have been referred to specialist mental health services and therefore Socrates offers an additional source of case identifications.

\section{Pharmaceutical collection (pharms)}

Pharms contains claim and payment information from pharmacists for government-subsidised medication dispensing throughout New Zealand [43]. Pharms data in the IDI were collected between 1 January 2005 and 31 December 2017. However, as pre-2007 data were collected with less than $90 \%$ coverage, only data collected from 2007 onwards were used for research purposes, as per $\mathrm{MoH}$ recommendations. 'Chemical IDs' assigned to each dispensing are used to identify the specific medication dispensed and can be used as indications for mental health problems.

The main advantage of pharms data is that they include information about both specialist and general practitioner prescribing. Therefore, pharms data provide some insights into mental healthcare activity at the primary care level. However, diagnostic information can only be inferred from pharmaceutical codes related to dispensing, therefore diagnoses derived from pharmaceutical data are less certain than those derived from PRIMHD and NMDS. They should be considered speculative because, while they provide information on dispensing of psychotropic medications, the use of any individual medication can be for a number of conditions. For the purposes of this paper, we have clustered data by the most likely use for a medication. At present, it is not possible within pharms to identify the health specialty of the prescriber (psychiatrist, general practitioner, or other medical practitioner) or the reason for the prescription [4].

\section{Mortality collection}

The mortality collection contains information about the underlying causes of all deaths registered in New Zealand [28]. It uses the ICD-10-AM classification and World Health Organization Rules and Guidelines for Mortality Coding [51]. Mortality data are robust and of high quality. However, due to the timeframe for coronial processes, there is a two-year lag in its availability. For the current analysis, the mortality dataset within the IDI was collected between 1 January 1988 and 31 December 2015 and has been used in this study to identify cases of death by suicide.

\section{Data summary}

Figure 1 displays the periods of time ${ }^{4}$ each of the five datasets are available within the IDI. It breaks down the coverage by 'available data' and 'best quality data' as per the discussions above. Data were available for each of the datasets within a five-fiscal year period from 1 July 2010 (start of 2010/11 fiscal year) until 30 June 2015 (end of 2014/15 fiscal year). For the purposes of demonstrating an application of the method we decided to use the most recent of these fiscal years, 2014/15. The results are presented in the next section.

${ }^{4}$ It is important to note that data in the IDI is updated periodically, typically quarterly. 


\section{Establishing and refining case definitions for mental health problems}

Our aim was to create a method for identifying common, clinically relevant mental health problems for New Zealand children and young people (aged 24 and under) using available IDI data, which also included self-harm. The method built on a similar approach taken by the Social Investment Agency (SIA) [40] but was developed specifically for children and young people. The twostage process undertaken to establish the case identification method is summarised below.

In the first stage, a short-list of 13 mental health (and related) problems of interest was derived by a clinically experienced team, based on the IDI data available. Our focus was on disorders that present to primary and secondary services. We were aware of the limitations of finer definition of problems because of the data available; for example, the sub-categories of anxiety disorder. For this reason, we chose broader categories that would allow us to make some limited assumptions about care in the primary setting that were sufficient for the purposes of population surveillance. Our final list comprised anxiety, depression, bipolar disorders, emotional problems (where anxiety and/or depression could not be reliably distinguished), ${ }^{5}$ disruptive behaviours, substance problems, eating problems, psychosis, personality disorders, sleep problems, self-harm, other mental health problems, ${ }^{6}$ and mental health not defined. ${ }^{7}$

The second stage of work involved the systematic classification and refinement of codes used to assign cases into each mental health problem category, by data source. A panel of eight specialists covering a diverse range of mental health disciplines (a clinical psychologist, four child and adolescent psychiatrists, two with dual qualifications as paediatricians, one with specific specialist expertise in substance-use disorders and three academic researchers in child and adolescent mental health) independently assigned diagnostic codes to the 13 mental health problem categories. Most data sources (NMDS, PRIMHD, Socrates, and the mortality collection) provided specific

\footnotetext{
${ }^{5}$ This is a composite group formed because a number of medications exist which are typically good indications of either Anxiety Disorders or Depressive Disorders but not specifically one in particular. There are several diagnostic codes that contribute to this group as well. ${ }^{6}$ This is a composite group, which for the sake of completeness includes all mental health diagnostic codes not otherwise used in the first ten groups.

${ }^{7}$ This is a composite group formed because a number of medications are typically indications for a range of potential mental health problems but not specific disorders and in many cases. 'Mental health not defined' is also a diagnostic code commonly assigned to people with mental health problems that for whatever reason cannot be specified with more detail.
}

diagnoses (e.g. ICD-10-AM or DSM-IV) that fit naturally into the 13 mental health problem categories. For pharmaceutical data, the panel's clinical expertise was utilised to infer the mental health problem according to the type of medication and patient age. Any disagreements were resolved by discussion and consensus. Five age strata $(0-4,5-9,10-14,15-19$, and 20-24) were defined and used to increase accuracy of inferred diagnoses. These age bands were used as recommended management strategies depend on developmental level [24]. In addition, secondary mental health services are approximately organised around these age bands. Our method of classification drew on clinical experience and took into account the prevalence of disorder and the likely treatment within these age bands. For example, Amitriptyline is not included in the rubric for depression in children and adolescents but is for those aged 20 years and over. Medications deemed to be used for both anxiety and depression were assigned to the category 'emotional disorders' (e.g. Fluoxetine) and medications used for several mental health problems (e.g. Risperidone, which may be used for the treatment of psychosis, disruptive behaviour, obsessive compulsive disorder, bipolar disorder and emotional dysregulation) to the category 'mental health not defined'. Medications considered more likely to be used for the treatment of non-mental health problems were entirely excluded. Details of all the individual codes used to determine each of the 13 mental health problem categories can be found in the Appendix.

The data sources used to identify each specific mental health problem group are outlined in Table 1. Some mental health problems were derived from as few as two datasets (e.g. eating problems were identified using NMDS and PRIHMD Diagnosis) and others

Table 1 Sources of data for each disorder group

\begin{tabular}{|c|c|c|c|c|c|}
\hline Mental Health Problems & NMDS & PRIMHD & Pharms & Socrates & Mortality \\
\hline Anxiety & $\checkmark$ & $\checkmark$ & $\checkmark$ & $\checkmark$ & \\
\hline Depression & $\checkmark$ & $\checkmark$ & $\checkmark$ & $\checkmark$ & \\
\hline Emotional Problems & $\checkmark$ & $\checkmark$ & $\checkmark$ & & \\
\hline Bipolar Disorders & $\checkmark$ & $\checkmark$ & & $\checkmark$ & \\
\hline Substance Problems & $\checkmark$ & $\checkmark$ & $\checkmark$ & $\checkmark$ & \\
\hline Eating Problems & $\checkmark$ & $\checkmark$ & & & \\
\hline Disruptive Behaviours & $\checkmark$ & $\checkmark$ & $\checkmark$ & $\checkmark$ & \\
\hline Psychosis & $\checkmark$ & $\checkmark$ & $\checkmark$ & $\checkmark$ & \\
\hline Personality Disorders & $\checkmark$ & $\checkmark$ & & $\checkmark$ & \\
\hline Sleep Problems & $\checkmark$ & $\checkmark$ & $\checkmark$ & & \\
\hline Self-harm & $\checkmark$ & & & & $\checkmark$ \\
\hline Other Mental Health & $\checkmark$ & $\checkmark$ & & & \\
\hline $\begin{array}{l}\text { Mental health not } \\
\text { defined }\end{array}$ & & $\checkmark$ & $\checkmark$ & $\checkmark$ & \\
\hline
\end{tabular}


from as many as four datasets (e.g. anxiety was identified using NMDS, PRIMHD, Pharms, and Socrates).

\section{Data management}

Data preparation was conducted in SAS 7.1 within the IDI environment. There were three main steps. First, event level data (e.g. medication dispensing for pharms, hospitalisations for NMDS) were extracted separately for each of the five datasets used in the study, for all individuals in the New Zealand youth population (0-24) for the 2014/15 fiscal year. Then, using the coding system for case identification described, 13 dichotomous mental health problem indicator variables were generated for each individual. Each dichotomous indicator was set to one if at least one code from the code list was found in any data source. Finally, data from each of the five datasets were appended and then collapsed to one set of mental health problem indicators per person. For individuals who had a 'mental health not defined' and another specific mental health problem group indicator (excluding self-harm) the 'mental health not defined' indicator was set to zero. The resulting data were analysed using StataMP 15. All counts were randomly rounded to base three in line with Statistics New Zealand confidentiality requirements.

\section{Establishing the New Zealand youth (0-24) population 2014/15}

The New Zealand youth population (0-24) was calculated using existing methods for estimating a resident New Zealand population from the IDI [18, 52]. More specifically, this method included people whose presence in New Zealand was indicated by activity in key datasets. Individuals who had died $^{8}$ or moved overseas were excluded. The total resident population generated using this method was within $2 \%$ of the official estimated resident population. Case identifications were restricted to people from within this population and 12-month prevalence rates were derived using this population as a denominator.

\section{Ethics approval}

The University of Otago Human Research Ethics Committee reviewed the study for ethics consideration. The study was reviewed as a 'Minimal Risk Health Research - Audit and Audit related Studies' proposal and was approved. Approval to access IDI data was granted by Statistics New Zealand.

\footnotetext{
${ }^{8}$ For fatal self-harm, the youth population for the previous fiscal year was used as the denominator to allow for mortality in the 2014/15 year.
}

\section{Results}

The case identification method was applied to data from the 2014/15 fiscal year. Over 82,000 unique individuals aged $0-24$ with at least one mental health problem indicator including self-harm, other mental health, and mental health not defined were identified (see Table 2), indicating a 12-month prevalence of 5318 per 100,000 population (equivalent to $5.3 \%$ ).

The most prevalent mental health problem subgroups were 'emotional problems' with 31,266 individuals (2.0\% of population), followed by substance problems with 16 , 314 individuals $(1.7 \%)$, and disruptive behaviours with 13,758 individuals $(0.9 \%)$.

Overall, pharms identified the greatest number of individuals (almost 60,000) and was also the data source used to identify the most individuals in six of the 13 problem groups (anxiety, depression, emotional problems, disruptive behaviours, psychosis, and sleep problems). PRIMHD was the data source that contributed the second most case identifications (over 32,000) and was the biggest contributor to a further six of 13 specific mental health problem groups (bipolar disorders, substance problems, eating problems, personality disorders, mental health not defined, and other mental health). NMDS was the only data source used to identify cases of non-fatal self-harm, and also contributed to the case identifications in all other mental health problem groups. Socrates was used in only eight of 13 mental health problem groups, however, while the corresponding case identifications numbers were generally low, it contributed to identifying nearly 600 disruptive behaviour cases.

\section{Discussion \\ Key findings}

We have proposed a method to identify and classify mental health problems among New Zealand children and young people using a range of data from the IDI. The method identified over 82,000 individuals aged between 0 and 24 with mental health problems, affecting 5.3\% of all youth in 2014/15. Not surprisingly, emotional disorders, when combined with specifically defined anxiety and depressive disorders, comprise, by far, the greatest number of treated mental health problems. This is followed by substance problems.

The method is not designed to estimate prevalence of all diagnosed mental conditions due to an undercount arising from relying mostly on secondary service use data. However, it does provide a method for identifying a population of individuals with mental health problems at least serious enough to require some level of public health funded intervention. Additionally, it can provide information to help to understand the use of mental health services and pharmaceuticals, and more broadly facilitate research on those affected by mental health problems. 
Table 2 Total Individuals by Disorder Group, Data Source and 12-month Population Prevalence Rates

\begin{tabular}{|c|c|c|c|c|c|c|c|}
\hline Mental Health Problem & PRIMHD & NMDS & Pharms & Socrates & Mortality & Total & Pop. Rate \\
\hline Emotional & 414 & 60 & 30,930 & & & 31,266 & 2020 \\
\hline Substance & 14,022 & 3072 & 267 & S & & 16,314 & $1742^{\mathrm{b}}$ \\
\hline Disruptive & 2772 & 177 & 12,414 & 591 & & 13,758 & 889 \\
\hline Anxiety & 3405 & 1377 & 6633 & 147 & & 10,512 & 679 \\
\hline Depression & 3288 & 1308 & 7116 & 21 & & 10,392 & 671 \\
\hline Sleep & 15 & 15 & 9549 & & & 9576 & 619 \\
\hline Psychosis & 972 & 855 & 990 & 9 & & 1881 & $201^{b}$ \\
\hline Eating & 1092 & 297 & & & & 1176 & 76 \\
\hline Personality & 414 & 276 & & S & & 552 & $119^{c}$ \\
\hline Bipolar & 327 & 210 & & S & & 420 & $65^{d}$ \\
\hline Sub Total (Any Problem) & 23,235 & 5715 & 54,417 & 693 & $n / a$ & 71,229 & 4602 \\
\hline MH not defined & 8613 & & 5445 & S & & 10,101 & 653 \\
\hline Self-harm & & 2766 & & & 108 & 2877 & 186 \\
\hline Other MH & 843 & 339 & & & & 1149 & 74 \\
\hline Total (Any Problem) & 32,400 & 7629 & 59,862 & 693 & 108 & 82,296 & 5318 \\
\hline
\end{tabular}

${ }^{a}$ Total unique individuals (across all data sources) per 100,000 youth (0-24) population (unless otherwise stated)

S Data suppressed due to number of case identifications being less than 6

${ }^{b}$ per 100,000 10-24 year old population

cper 100,000 18-24 year old population

dper 100,000 15-24 year old population

The results clearly demonstrate the value of utilising multiple datasets within the IDI, as there was no single dataset that performed well across all categories. The pharmaceutical collection data contributed the highest number of case identifications overall, however, in a number of mental health problem groups, other datasets were the main contributors, e.g. PRIMHD (substance) and NMDS (self-harm).

Having a method that can be used to simultaneously identify a range of mental health problems, including selfharm, at the individual level, and be able to link these data to other data sources (including non-health) could begin to set a framework to address important questions such as risk and protective factors, long term outcomes, health trajectories and burden of disease estimates for individuals with chronic mental health conditions.

\section{Limitations and strengths}

A limitation of this method is the current lack of formal validation against other data sources. Formal validation would be useful for two reasons. First, it could establish whether the diagnoses recorded in administrative data and those inferred from pharmaceutical dispensing have been correctly assigned. This is typically done through a detailed review of medical or case notes [13, 25]. Second, validation could measure the level of undercount in the identified population, and the extent to which this undercount varies for different age, sex, ethnic, and other groups. One approach to measuring undercount is to compare our method against a dataset in which there is a complete record of mental health diagnoses, such as a sample survey or registry that contains complete information for a subset of the population [7, 32]. This may be possible in the future as the New Zealand Health Survey [30], which contains mental health information that may be useful for validation, is scheduled for inclusion in the IDI, but is not currently available. In the absence of a survey or other dataset containing complete mental health diagnosis information, statistical approaches such as capture-recapture may be useful to estimate the extent of undercount. These have been used previously with New Zealand administrative health data [22, 23], although they are not without challenges, in particular ensuring that the independence assumption is met [23].

The absence of primary care data means that people treated in primary care without medication (for example, those who are referred to brief intervention services or other publicly or privately funded psychological therapy) are not captured with existing datasets. Pharms data provides a way to account for people treated in primary care, however, it is the weakest dataset used in terms of clinical detail and accuracy. There is an increased risk of false positive case identifications when using pharmaceutical indications because some medications can be prescribed for non-mental health problems (e.g. amitriptyline for neuropathic pain). We have attempted to mitigate this risk by excluding medications that are considered to be used mostly for non-mental health problems, and imposing age restrictions on others to increase the likelihood that they are being used for mental 
health. However, until a formal validation process can be undertaken, the risk of over-identification remains and the assignment of diagnostic categories using medications should be considered an informed guess rather than a definitive classification.

The structure of the data sets and missing data from major and important sectors, such as the primary healthcare sector, means that this method should be considered with caution and treated as a first attempt to make sense of the national data. We have used a careful and transparent process to assign codes, with input from experts from a range of relevant backgrounds. Although multiple individuals were involved in assigning mental health codes to problem group categories for case identification, limited engagement was undertaken with clinical coders (those who ascribe diagnosis codes based on clinical records) and other clinicians and stakeholders, and this may have limited the accurate interpretation of data.

The case identification method described is based on administrative data that measures service use rather than prevalence of mental health problems. From epidemiological studies we know that for many common disorders such as depression and anxiety, the majority of young people do not access services. Therefore, the prevalence rates in this paper are likely to be lower than rates derived from surveys or other sources that are not based on service use. In addition, as evidenced by the large number of problems classified 'not defined', not all mental health problems can be classified using this method. Given that mental health problems are comprised of overlapping symptom clusters with often limited temporal stability, there may never be a perfect way to identify and track them using administrative data. Furthermore, administrative data lacks clinical detail and often has known quality issues, both of which may affect the accuracy of case identification.

The approach presented in this paper is not a panacea for mental health research in the IDI. Rather, it is an example of a broad approach that could be tailored by other researchers to suit the needs of their individual projects. For example, researchers may wish to exclude cases identified by medications if they want to minimise uncertainty. Furthermore, researchers should be aware of, and make explicit, the limitations of the method and contributing data sources. These limitations notwithstanding, the method provides a better means for identifying mental health problems than existing methods using single source service use data.

\section{Ethical issues}

The secondary use of administrative data for research purposes is legal in New Zealand. The development of this administrative data into large linked data sources such as the IDI has raised issues around ethics and guidelines. Further discussion of these issues will be critical to the ongoing development and use of IDI data to ensure ethical use. The increased analytical power of such linked datasets needs to be balanced with the right to privacy for individuals, the lack of true informed consent, issues of data ownership in life and death, the veracity and completeness of available information, mechanisms for managing unexpected findings and agreed limits to the usage of data [11]. The possibility that continual comparison with other ethnic groups could disadvantage Māori and Pasifika people, who already face disparities in health, mental health and in a number of other areas, must be considered. Furthermore, that universal measures may not address the needs of specific cultural populations [9] should be borne in mind when applying data from this source.

\section{Further research and potential uses}

Further research is needed to formally validate and potentially refine the described method. This may be undertaken initially using New Zealand Health Survey data that is scheduled to be uploaded into the IDI. Alternative approaches could include medical record review from either primary or secondary care data or capturerecapture methods. The development of a truly robust method is likely to be iterative and might include code weighting and further refinement of age restrictions or code allocations once a data source is available to validate against. Once validity has been demonstrated, the method could be used to track mental health problems in children and young people over time to better understand pathways to risk and resilience. The IDI method could also be used for evaluating the long-term impact of public mental health interventions and, in time, reducing health disparities and inequalities.

\section{Conclusion}

We have described how multiple data sources from within the IDI can be used to identify and classify mental health problems according to secondary service use and medication dispensing data among New Zealand children and young people. This novel approach enables improved capabilities for mental health research and evaluation, however its current limitations should be kept firmly in mind. It could be further strengthened by the inclusion of additional data sources in the IDI, in particular primary care data. Undertaking a formal validation would allow for greater confidence in validity and also highlight areas where improvements can be made. The creation of the IDI is an important step forward in tracking health and well-being in New Zealand, but it is a new resource and ongoing work is needed to fully realise its potential for mental health research. 


\section{Appendix}

Table 3 Codes Sets Used to Identify Mental Health Problem Groups

\begin{tabular}{|c|c|c|c|c|c|}
\hline $\begin{array}{l}\text { Mental Health } \\
\text { Problem Group }\end{array}$ & NMDS (ICD-10-AM) & $\begin{array}{l}\text { PRIMHD (DSM-IV plus ICD- } \\
10-A M \text { codes listed under } \\
\text { NMDS) }\end{array}$ & $\begin{array}{l}\text { PRIMHD } \\
\text { Team type / } \\
\text { Activity type }\end{array}$ & Pharmaceuticals & Socrates \\
\hline Anxiety & $\begin{array}{l}\text { ICD-10-AM =F411, F4000 }{ }^{b}, \\
F 401^{\mathrm{a}}, F 402, F 408, F 409, \\
F 931, F 4001^{b}, F 410^{b}, F 412, \\
F 413, F 418, F 419, F 064, F 932, \\
F 420^{a}, F 421^{a}, F 422^{a}, F 428^{a}, \\
F 429^{a}, F 450, F 451, F 452, \\
F 4530, F 4531, F 4532, F 4533, \\
F 4534, F 4535, F 4538, F 4539, \\
F 454, F 458, F 459, F 480, F 680, \\
F 681, F 930, F 430, F 431, F 432, \\
F 438, F 439\end{array}$ & $\begin{array}{l}\text { DSM-IV }=30,002,30,029,30, \\
022^{b}, 30023^{a}, 30,001^{b}, 30 \\
021^{b}, 30,000,29,384,31,323 \\
3003^{a}, 3007,30,081,30,082 \\
30,780,30,789,30,016,30, \\
019,30,921,3083,30,981,30, \\
924,30,928\end{array}$ & None & $\begin{array}{l}\text { Chemical ID =6006, 1166, } \\
1780,2632,1911,1080^{c}, \\
1730^{b}, 1316^{b}, 2636 \text { (age 5-9 } \\
\text { only) }\end{array}$ & $\begin{array}{l}\text { Assigned } \\
\text { diagnosis } \\
\text { code }= \\
1302\end{array}$ \\
\hline Depression & 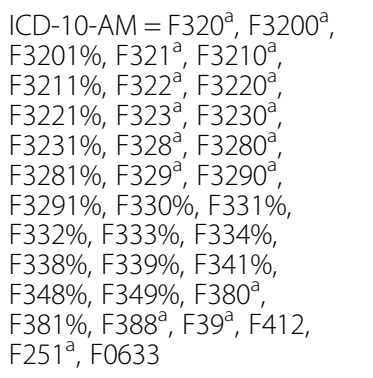 & $\begin{array}{l}\text { DSM-IV }=30,928,29,620^{\mathrm{a}}, \\
29621^{\mathrm{a}}, 29622^{\mathrm{a}}, 29623^{\mathrm{a}}{ }^{\prime} \\
29624^{\mathrm{a}}, 29625^{\mathrm{a}}, 29626^{\mathrm{a}}, 29, \\
630,29,631,29,632,29,633, \\
29,634,29,635,29,636^{\mathrm{c}}, \\
29690^{\mathrm{a}}, 3004^{\mathrm{a}}, 3090^{\mathrm{a}}, 311^{\mathrm{a}}\end{array}$ & None & $\begin{array}{l}\text { Chemical ID }=1437,1438 \\
3753,1824,2285,2301 \\
3901,1760,2638,1180 \\
3785,1379^{c}, 1642^{d}, 1059^{e}\end{array}$ & $\begin{array}{l}\text { Assigned } \\
\text { diagnosis } \\
\text { code }= \\
1304\end{array}$ \\
\hline Emotional Problems & $\begin{array}{l}\text { ICD-10-AM = F938, F939, } \\
F 928, F 929, F 252^{b}, F 258^{b} \\
F 063, F 0630, F 0634, F 0639 \\
F 920\end{array}$ & DSM-IV = 3094, 3099, 29,383 & None & $\begin{array}{l}\text { Chemical ID }=2636^{b}, 3926^{b} \\
3927^{b}, 1030^{b}, 1193^{b}, 1190^{b} \\
1955,6009,1069,1125^{c}\end{array}$ & None \\
\hline Bipolar Disorders ${ }^{c}$ & $\begin{array}{l}\text { ICD-10-AM =F310, F311, } \\
\text { F312, F313, F314, F315, F316, } \\
\text { F317, F318, F319, F300, F301, } \\
\text { F302, F308, F309, F340, } \\
\text { F0631, F0632 }\end{array}$ & $\begin{array}{l}\text { DSM-IV }=29,600,29,601,29 \\
602,29,603,29,604,29,605 \\
29,606,29,640,29,641,29 \\
642,29,643,29,644,29,645 \\
29,646,29,650,29,651,29 \\
652,29,653,29,654,29,655 \\
29,656,29,660,29,661,29 \\
662,29,663,29,664,29,665 \\
29,666,2967,29,680,29,689 \\
30,113\end{array}$ & None & None & $\begin{array}{l}\text { Assigned } \\
\text { diagnosis } \\
\text { code }= \\
1303\end{array}$ \\
\hline Substance Problems ${ }^{\mathrm{b}}$ & $\begin{array}{l}\text { ICD-10-AM=F100, F101, } \\
\text { F102, F103, F104, F105, F106, } \\
\text { F107, F108, F109, F110, F111, } \\
\text { F112, F113, F114, F115, F116, } \\
\text { F117, F118, F119, F120, F121, } \\
\text { F122, F123, F124, F125, F126, } \\
\text { F127, F128, F129, F130, F131, } \\
\text { F132, F133, F134, F135, F136, } \\
\text { F137, F138, F139, F140, F141, } \\
\text { F142, F143, F144, F145, F146, } \\
\text { F147, F148, F149, F150, F151, } \\
\text { F152, F153, F154, F155, F156, } \\
\text { F157, F158, F159, F160, F161, } \\
\text { F162, F163, F164, F165, F166, } \\
\text { F167, F168, F169, F180, F181, } \\
\text { F182, F183, F184, F185, F186, } \\
\text { F187, F188, F189, F190, F191, } \\
\text { F192, F193, F194, F195, F196, } \\
\text { F197, F198, F199, F550, F551, } \\
\text { F552, F553, F554, F555, F556, } \\
\text { F558, F559 }\end{array}$ & $\begin{array}{l}\text { DSM-IV }=30,300,30,500,30 \\
390,2910,2913,2915,29, \\
181,29,189,2919,30,430,30 \\
520,30,400,30,550,30,410 \\
30,540,30,480,30,490,30 \\
420,30,560,30,450,30,530 \\
30,460,30,590,2920,29,211 \\
29,212,29,281,29,284,29 \\
289,2929,30,440,30,570\end{array}$ & $\begin{array}{l}\text { Activity } \\
\text { type = T16, } \\
\text { T17, T18, } \\
\text { T19, T20, } \\
\text { and/or } \\
\text { Team } \\
\text { type }=3\end{array}$ & $\begin{array}{l}\text { Chemical ID =2367, } 1432 \\
\text { 1841, } 3950,1795,3793 \\
1252,1273\end{array}$ & $\begin{array}{l}\text { Assigned } \\
\text { diagnosis } \\
\text { code }= \\
1301\end{array}$ \\
\hline Eating Problems & $\begin{array}{l}\text { ICD-10-AM = F500 }{ }^{b}, F 501^{b} \\
F 502^{b}, F 503^{b}, F 508, F 509, \\
F 982, F 983\end{array}$ & $\begin{array}{l}\text { DSM-IV }=3071^{b}, 30750^{a}, 30 \\
751^{b}, 30,752,30,753,30,759\end{array}$ & $\begin{array}{l}\text { Team } \\
\text { type }=16\end{array}$ & None & None \\
\hline Disruptive Behaviours & ICD-10-AM = F900, F908, & DSM-IV $=31,400,31,401$ & None & Chemical ID $=3887^{\mathrm{a}}, 1809$ & Assigned \\
\hline
\end{tabular}


Table 3 Codes Sets Used to Identify Mental Health Problem Groups (Continued)

\begin{tabular}{|c|c|c|c|c|c|}
\hline $\begin{array}{l}\text { Mental Health } \\
\text { Problem Group }\end{array}$ & NMDS (ICD-10-AM) & $\begin{array}{l}\text { PRIMHD (DSM-IV plus ICD- } \\
10-A M \text { codes listed under } \\
\text { NMDS) }\end{array}$ & $\begin{array}{l}\text { PRIMHD } \\
\text { Team type / } \\
\text { Activity type }\end{array}$ & Pharmaceuticals & Socrates \\
\hline & $\begin{array}{l}\text { F909, F901, F910, F911, F912, } \\
\text { F918, F919, F920, F928, F929, } \\
\text { F913, F631, F632, F638, F639 }\end{array}$ & $\begin{array}{l}3149,3093,3094,31,281,31 \\
282,31,289,3129,31,381,31 \\
230,31,232,31,233,31,234 \\
\text { V7102 }\end{array}$ & & 3880,1389 & $\begin{array}{l}\text { diagnosis } \\
\text { code = } \\
1201 \\
1307\end{array}$ \\
\hline Psychosis $^{b}$ & $\begin{array}{l}\text { ICD-10-AM = F200, F201, } \\
\text { F202, F203, F204, F205, F206, } \\
\text { F208, F209, F21, F220, F228, } \\
\text { F229, F230, F231, F232, F233, } \\
\text { F238, F239, F24, F250, F251, } \\
\text { F252, F258, F259, F28, F29, } \\
\text { F105, F115, F125, F135, F145, } \\
\text { F155, F165, F175, F185, F195 }\end{array}$ & $\begin{array}{l}\text { DSM-IV }=29,510,29,520,29 \\
530,29,540,29,560,29,570 \\
29,590,2971,2973,2988 \\
2989,2913,2915,29,211,29 \\
212,29,381,29,382\end{array}$ & $\begin{array}{l}\text { Activity } \\
\text { type = T09 }\end{array}$ & $\begin{array}{l}\text { Chemical ID = 3884, 1078, } \\
\text { 1532, 2820, 1732, 1990, } \\
1994,2255,2260,1533, \\
1535,1950,3873,1007,1226, \\
1283,1583,1799,2298, \\
2530,3803,3898,3940,4025, \\
8792\end{array}$ & $\begin{array}{l}\text { Assigned } \\
\text { diagnosis } \\
\text { code }= \\
1306\end{array}$ \\
\hline Personality Disorders ${ }^{\mathrm{e}}$ & $\begin{array}{l}\text { ICD-10-AM = F600, F601, } \\
\text { F602, F6030, F6031, F604, } \\
\text { F605, F606, F607, F608, F609, } \\
\text { F61, F620, F621, F628, F629, } \\
\text { F070 }\end{array}$ & $\begin{array}{l}\text { DSM-IV }=3010,3019,30,120 \\
30,122,3014,30,150,3016 \\
3017,30,181,30,182,30,183\end{array}$ & None & None & None \\
\hline Sleep Problems & $\begin{array}{l}\text { ICD-10-AM = F510, F511, } \\
F 512, F 518, F 519, F 513, F 514 \\
F 515\end{array}$ & $\begin{array}{l}\text { DSM-IV }=30,742,30,744,30 \\
745,347,78,052,78,059,30 \\
746,30,747\end{array}$ & None & Chemical ID $=3735,2484^{C}$ & None \\
\hline $\begin{array}{l}\text { Self-harm (self-harm } \\
\text { also uses the ICD-10- } \\
\text { AM codes listed } \\
\text { under NMDS within } \\
\text { mortality collection } \\
\text { data) }\end{array}$ & $\begin{array}{l}\text { ICD-10-AM =X60,X61,X62, } \\
X 63, X 64, X 65, X 66, X 67, X 68, \\
X 69, X 70, X 71, X 72, X 73, X 74, \\
X 75, X 76, X 77, X 78, X 79, X 80, \\
X 81, X 82, X 83, X 84, Y 870\end{array}$ & None & None & None & None \\
\hline Other Mental Health & $\begin{array}{l}\text { ICD-10-AM = F050, F051, } \\
\text { F058, F059, F060, F061, F062, } \\
\text { F065, F066, F068, F069, F071, } \\
\text { F072, F078, F079, F09, F488, } \\
\text { F489, F633, F842, F843, F950, } \\
\text { F951, F952, F958, F959, F980, } \\
\text { F981, F984, F988, F989, F99, } \\
\text { F630 }\end{array}$ & $\begin{array}{l}\text { DSM-IV }=2930,29,389,2939 \\
29,910,30,720,30,721,30 \\
722,30,723,3073,3076 \\
3077,31,239,31,382,31,389 \\
3139,78,009,7876,31,231^{b}\end{array}$ & None & None & None \\
\hline $\begin{array}{l}\text { Mental health not } \\
\text { defined }\end{array}$ & None & DSM-IV = V7109, 3009, 7999 & None & $\begin{array}{l}\text { Chemical ID }=2466^{\mathrm{c}}, 3878^{\mathrm{a}}, \\
1315^{\mathrm{a}}, 1140^{\mathrm{a}}, 1183^{\mathrm{a}}, 1011^{\mathrm{a}}, \\
1729,1731,2295,1397, \\
1865,2224,2436,3892 \\
6007^{\mathrm{c}}\end{array}$ & $\begin{array}{l}\text { Assigned } \\
\text { diagnosis } \\
\text { code = } \\
1399\end{array}$ \\
\hline
\end{tabular}

${ }^{a}$ Restricted to ages 5+

b Restricted to ages $10+$

c Restricted to ages $15+$

d Restricted to ages $20+$

e Restricted to ages 18+

Table 4 Team Type and Activity Type Concordance (PRIMHD)

\begin{tabular}{ll}
\hline Team/Activity Type Code & Description \\
\hline 3 & Alcohol and drug services \\
16 & Eating Disorder Team \\
T09 & Early psychosis intervention attendances \\
T16 & Substance abuse Withdrawal management \\
T17 & /detoxification occupied bed nights (medical) \\
T18 & Substance abuse detoxification attendances (social) \\
T19 & Methadone treatment specialist service attendances \\
T20 & Methadone treatment specialist service attendances \\
\hline
\end{tabular}


Table 5 Chemical Code Concordance (Pharmaceutical Collection)

\begin{tabular}{|c|c|}
\hline Chemical Code & Description \\
\hline 1007 & Sulpiride \\
\hline 1011 & Risperidone \\
\hline 1030 & Sertraline Hydrochloride \\
\hline 1059 & Amitriptyline \\
\hline 1069 & Amoxapine \\
\hline 1078 & Clozapine \\
\hline 1080 & Amylobarbitone sodium \\
\hline 1125 & Nefazodone \\
\hline 1140 & Olanzapine \\
\hline 1166 & Bromazepam \\
\hline 1180 & Venlafaxine \\
\hline 1183 & Quetiapine \\
\hline 1190 & Citalopram hydrobromide (Celapram) \\
\hline 1193 & Citalopram \\
\hline 1226 & Zuclopenthixol dihydrochloride \\
\hline 1252 & Naltrexone hydrochloride \\
\hline 1273 & Chlormethiazole edisylate \\
\hline 1283 & Chlorpromazine hydrochloride \\
\hline 1315 & Clomipramine hydrochloride \\
\hline 1316 & Clonazepam \\
\hline 1379 & Desipramine hydrochloride \\
\hline 1389 & Dexamfetamine \\
\hline 1397 & Diazepam \\
\hline 1432 & Disulfiram \\
\hline 1437 & Dosulepin (Dothiepin) hydrochloride \\
\hline 1438 & Doxepin hydrochloride \\
\hline 1532 & Flupenthixol decanoate \\
\hline 1533 & Fluphenazine decanoate \\
\hline 1535 & Fluphenazine hydrochloride \\
\hline 1583 & Haloperidol \\
\hline 1642 & Imipramine hydrochloride \\
\hline 1729 & Loprazolam mesylate \\
\hline 1730 & Lorazepam \\
\hline 1731 & Lormetazepam \\
\hline 1732 & Lozapine succinate \\
\hline 1760 & Maprotiline hydrochloride \\
\hline 1780 & Meprobamate \\
\hline 1795 & Methadone hydrochloride \\
\hline 1799 & Levomepromazine maleate \\
\hline 1809 & methylphenidate hydrochloride \\
\hline 1824 & Mianserin hydrochloride \\
\hline 1841 & Naloxone hydrochloride \\
\hline 1865 & Nitrazepam \\
\hline
\end{tabular}

Table 5 Chemical Code Concordance (Pharmaceutical Collection) (Continued)

\begin{tabular}{|c|c|}
\hline Chemical Code & Description \\
\hline$\overline{1911}$ & Oxazepam \\
\hline 1950 & Pericyazine \\
\hline 1955 & Phenelzine sulphate \\
\hline 1990 & Pimozide \\
\hline 1994 & Pipotiazine palmitate \\
\hline 2224 & Temazepam \\
\hline 2255 & Thioridazine hydrochloride \\
\hline 2260 & Thiothixene \\
\hline 2285 & Tranylcypromine sulphate \\
\hline 2295 & Triazolam \\
\hline 2298 & Trifluoperazine hydrochloride \\
\hline 2301 & Trimipramine maleate \\
\hline 2367 & Calcium carbimide \\
\hline 2436 & Flunitrazepam \\
\hline 2466 & Lithium Carbonate \\
\hline 2530 & Haloperidol decanoate \\
\hline 2632 & Alprazolam \\
\hline 2636 & Fluoxetine \\
\hline 2636 & Fluoxetine hydrochloride \\
\hline 2638 & Moclobemide \\
\hline 2820 & Fluspirilene \\
\hline 3753 & Mirtazapine \\
\hline 3785 & Venlafaxine \\
\hline 3793 & Naltrexone hydrochloride \\
\hline 3803 & Zuclopenthixol decanoate \\
\hline 3873 & Ziprasidone \\
\hline 3878 & Aripiprazole \\
\hline 3880 & methylphenidate hydrochloride extended-release \\
\hline 3884 & Amisulpride \\
\hline 3887 & Atomoxetine \\
\hline 3892 & Bupropion hydrochloride \\
\hline 3898 & Zuclopenthixol hydrochloride \\
\hline 3901 & Mirtazapine \\
\hline 3926 & Escitalopram \\
\hline 3927 & Sertraline \\
\hline 3940 & Olanzapine pamoate monohydrate \\
\hline 3950 & Buprenorphine with naloxone \\
\hline 4025 & Paliperidone \\
\hline 6006 & Buspirone hydrochloride \\
\hline 6007 & Chlordiazepoxide hydrochloride \\
\hline 6009 & Paroxetine hydrochloride \\
\hline 8792 & Droperidol \\
\hline
\end{tabular}


Table 6 Assigned Diagnosis Code Concordance (Socrates)

\begin{tabular}{ll}
\hline Assigned Diagnosis Code & Description \\
\hline 1201 & $\begin{array}{l}\text { Attention deficit / hyperactivity, } \\
\text { (e.g. ADD, ADHD) }\end{array}$ \\
1301 & $\begin{array}{l}\text { Alcohol / drug related disorder } \\
\text { (excluding Korsakov's syndrome) }\end{array}$ \\
1302 & Anxiety disorders \\
1303 & Bipolar disorder (manic depression) \\
1304 & Depression \\
1307 & Behavioural problem / issue, \\
1306 & type not specified \\
1399 & Schizophrenia \\
& Other psychiatric disorder (specific)
\end{tabular}

\section{Abbreviations}

ADHD: Attention deficit and hyperactivity disorder; DHB: District health board; DSM: Diagnostic and Statistical Manual of Mental Disorders; ICD: International Classification for Diseases; MoH: Ministry of Health; NASC: Needs Assessment and Service Co-ordination Agency; NGO: Nongovernmental organisation; NMDS: National Minimum Dataset: Pharms: Pharmaceutical collection; PRIMHD: Programme for the Integration of Mental Health Data; SIA: Social Investment Agency

\section{Acknowledgements}

We would also like to acknowledge Dr. Grant Christie, University of Auckland, and Dr. Rebecca Mairs, University of Auckland for their contributions.

\section{Consent of publication}

Not applicable with respect to individual/person level data. Consent for publication of the data presented in this paper, subject to the disclaimer presented, has been given by Statistics New Zealand.

\section{Disclaimer}

The results in this paper are not official statistics. They have been created for research purposes from the Integrated Data Infrastructure (IDI), managed by Statistics New Zealand. The opinions, findings, recommendations, and conclusions expressed in this paper are those of the authors, not Statistics New Zealand.

Access to the anonymised data used in this study was provided by Statistics New Zealand under the security and confidentiality provisions of the Statistics Act 1975. Only people authorised by the Statistics Act 1975 are allowed to see data about a particular person, household, business, or organisation, and the results in this paper have been confidentialised to protect these groups from identification and to keep their data safe. Careful consideration has been given to the privacy, security, and confidentiality issues associated with using administrative and survey data in the IDI. Further detail can be found in the Privacy impact assessment for the Integrated Data Infrastructure available from www.stats.govt.nz.

\section{Authors' contributions}

All listed authors have made substantial contributions to the manuscript and have approved the submitted version. They have aggreged to be personally accountable for their contributions, and ensure that questions related to the accuracy or integrity of any part of the work, even ones in which the author was not personally involved, are appropriately investigated, resolved, and the resolution documented in the literature: NB: Design and conception of work, diagnostic classification, coding, analysis, writing of manuscript. SG: Design and conception of work, diagnostic classification, coding, analysis, writing of manuscript. HT: Design and conception of work, diagnostic classification, writing of manuscript. JK: Design and conception of work, diagnostic classification, coding, analysis, substantial revisions of work. RA: Design and conception of work, substantial revisions of work. SM: Design and conception of work, diagnostic classification, writing of manuscript. BT: Design and conception of work, substantial revisions of work. SH: Design and conception of work, diagnostic classification, writing of manuscript.

\section{Funding}

This research was part of A Better Start National Science Challenge, funded by the New Zealand Ministry of Business, Innovation and Employment (MBIE); tranche 1 project, UOAX1511. The funders had no role in study design, data collection and analysis, decision to publish, or preparation of the manuscript.

\section{Availability of data and materials}

The data used in this study are held with the Integrated Data Infrastructure and are managed by Statistics New Zealand. These data are publicly available, although access to is restricted. Please see https://www.stats.govt. nz/integrated-data/integrated-data-infrastructure/ for more details.

The SAS code will be made available to interested parties.

\section{Ethics approval and consent to participate}

The University of Otago Human Research Ethics Committee reviewed the study for ethics consideration. The study was reviewed as a 'Minimal Risk Health Research - Audit and Audit related Studies' proposal and was approved.

\section{Competing interests}

The authors declare that they have no competing interests.

\section{Author details}

${ }^{1}$ A Better Start National Science Challenge, Auckland, New Zealand. 2Department of Women's and Children's Health, University of Otago, 201 Great King St, Dunedin 9016, New Zealand. ${ }^{3}$ Department of Public Health, University of Otago Wellington, 23 Mein St, Newtown, Wellington 6021, New Zealand. ${ }^{4}$ Department of Psychological Medicine, University of Auckland, 22-30 Park Ave Grafton, Auckland 1023, New Zealand. ${ }^{5}$ Centre for Pacific Health, Va'a O Tautai, Health Sciences Division, University of Otago, 71 Frederick St, Dunedin 9016, New Zealand. ${ }^{6}$ Dean of the Otago Medical School, University of Otago, 290 Great King St, Dunedin 9016, New Zealand.

Received: 9 July 2019 Accepted: 17 February 2020

Published online: 27 February 2020

\section{References}

1. Aronsky D, Haug PJ, Lagor C, Dean NC. Accuracy of administrative data for identifying patients with pneumonia. Am J Med Qual. 2005;20(6):319-28.

2. Atkinson J, Blakely T. New Zealand's integrated data infrastructure (IDI): value to date and future opportunities. Int J Population Data Sci. 2017;1(1): 105.

3. Blakely TA, Collings SC, Atkinson J. Unemployment and suicide. Evidence for a causal association? J Epidemiol Community Health. 2003;57(8):594-600.

4. Bowden N, Gibb S, Thabrew H, Audas R, Camp J, Taylor B, Hetrick S. IDI trends in antidepressant dispensing to New Zealand children and young people between 2007/08 and 2015/16. N Z Med J. 2019:132(1505):48-61.

5. Cadarette $S M$, Wong L. An introduction to health care administrative data. Can J Hosp Pharm. 2015;68(3):232.

6. Chen H, Cohen P, Kasen S, Johnson JG, Berenson K, Gordon K. Impact of adolescent mental disorders and physical illnesses on quality of life 17 years later. Arch Pediatr Adolesc Med. 2006;160(1):93-9.

7. Dart AB, Martens PJ, Sellers EA, Brownell MD, Rigatto C, Dean HJ. Validation of a pediatric diabetes case definition using administrative health data in Manitoba, Canada. Diabetes Care. 2011;34(4):898-903. https://doi.org/10. 2337/dc10-1572

8. Davis KA, Sudlow CL, Hotopf M. Can mental health diagnoses in administrative data be used for research? A systematic review of the accuracy of routinely collected diagnoses. BMC Psychiatry. 2016;16(1):263.

9. Durie M. Measuring Māori wellbeing. New Zealand Treasury Guest Lecture Ser. 2006;1:2007-09.

10. Elixhauser A, Steiner C, Harris DR, Coffey RM. Comorbidity measures for use with administrative data. Med Care. 1998;36:8-27.

11. European Economic and Social Committee. (2017). The ethics of Big Data: Balancing economic benefits and ethical questions of Big Data in the EU policy context. Retrieved from https://www.eesc.europa.eu/resources/docs/qe-02-1 7-159-en-n.pdf

12. Fergusson DM, Boden JM, Horwood L. Recurrence of major depression in adolescence and early adulthood, and later mental health, educational and economic outcomes. Br J Psychiatry. 2007;191(4):335-42. 
13. Fiest KM, Jette N, Quan H, St. Germaine-Smith C, Metcalfe A, Patten SB, Beck CA. Systematic review and assessment of validated case definitions for depression in administrative data. BMC Psychiatry. 2014;14(1):289. https:// doi.org/10.1186/s12888-014-0289-5.

14. Fleming TM, Clark T, Denny S, Bullen P, Crengle S, Peiris-John R, et al. Stability and change in the mental health of New Zealand secondary school students 2007-2012: results from the national adolescent health surveys. Aust New Zealand J Psychiatry. 2014;48(5):472-80.

15. Frayne SM, Miller DR, Sharkansky EJ, Jackson W, Wang F, Halanych JH, et al. Using administrative data to identify mental illness: what approach is best? Am J Med Qual. 2010;25(1):42-50.

16. Frisk M. A complex background in children and adolescents with psychiatric disorders: developmental delay, dyslexia, heredity, slow cognitive processing and adverse social factors in a multifactorial entirety. Eur Child Adolesc Psychiatry. 1999:8(3):225-36.

17. Garland A, Gershengorn HB, Marrie RA, Reider N, Wilcox ME. A practical, global perspective on using administrative data to conduct intensive care unit research. Ann Am Thorac Soc. 2015;12(9):1373-86.

18. Gibb S, Bycroft C, Matheson-Dunning N. Identifying the New Zealand resident population in the integrated data infrastructure (IDI). In: Statistics New Zealand: 2016.

19. Harvey SB, Deady M, Wang M-J, Mykletun A, Butterworth P, Christensen H, Mitchell PB. Is the prevalence of mental illness increasing in Australia? Evidence from national health surveys and administrative data, 2001-2014. Med J Aust. 2017;206(11):490-3.

20. Hebert PL, Geiss LS, Tierney EF, Engelgau MM, Yawn BP, McBean AM. Identifying persons with diabetes using Medicare claims data. Am J Med Qual. 1999;14(6):270-7.

21. Hinds A, Lix LM, Smith M, Quan H, Sanmartin C. Quality of administrative health databases in Canada: a scoping review. Can J Public Health. 2016; 107(1):56-61.

22. Jackson G, Wright C, Thornley S, Taylor WJ, Te Karu L, Gow PJ, et al. Potential unmet need for gout diagnosis and treatment: capture-recapture analysis of a national administrative dataset. Rheumatology. 2012;51(10): 1820-4. https://doi.org/10.1093/rheumatology/kes147.

23. Kake T, Arnold R, Ellis P. Estimating the prevalence of schizophrenia among New Zealand Maori: a capture-recapture approach. Aust N Z J Psychiatry. 2008:42(11):941-9. Retrieved from. https://doi.org/10.1080/00048670802415376.

24. Kessler RC, Berglund P, Demler O, Jin R, Merikangas KR, Walters EE. Lifetime prevalence and age-of-onset distributions of DSM-IV disorders in the National Comorbidity Survey Replication. Arch Gen Psychiatry. 2005;62(6): 593-602.

25. Kim HM, Smith EG, Stano CM, Ganoczy D, Zivin K, Walters H, Valenstein M. Validation of key behaviourally based mental health diagnoses in administrative data: suicide attempt, alcohol abuse, illicit drug abuse and tobacco use. BMC Health Serv Res. 2012;12(1):18. https://doi.org/10.1186/ 1472-6963-12-18.

26. Mazzali C, Duca P. Use of administrative data in healthcare research. Intern Emerg Med. 2015:10(4):517-24.

27. Ministry of Health. Looking forward: strategic directions for the mental health services. 1994. Retrieved from Wellington, NewZealand: https://www. moh.govt.nz/notebook/nbbooks.nsf/0/DAA659934A069A234C2565D7001 8A75A/\$file/looking-forward.pdf.

28. Ministry of Health. (2017a). Mortality collection data dictionary. In. Wellington.

29. Ministry of Health. (2017b). PRIMHD classification - summary and metadata. Retrieved from Wellington:

30. Ministry of Health. (2019). New Zealand Health Survey. Retrieved from https://www.health.govt.nz/nz-health-statistics/national-collections-andsurveys/surveys/new-zealand-health-survey

31. Mojtabai R, Stuart EA, Hwang I, Susukida R, Eaton WW, Sampson N, Kessler RC. Long-term effects of mental disorders on employment in the National Comorbidity Survey ten-year follow-up. Soc Psychiatry Psychiatr Epidemiol. 2015:50(11):1657-68

32. Muggah E, Graves E, Bennett C, Manuel DG. Ascertainment of chronic diseases using population health data: a comparison of health administrative data and patient self-report. BMC Public Health. 2013;13(1):16. https://doi.org/10.1186/1471-2458-13-16.

33. Neff JM, Sharp VL, Muldoon J, Graham J, Popalisky J, Gay JC. Identifying and classifying children with chronic conditions using administrative data with the clinical risk group classification system. Ambul Pediatr. 2002;2(1):71-9.
34. New Zealand Statutes. (1993). Privacy act. In

35. Polanczyk GV, Salum GA, Sugaya LS, Caye A, Rohde LA. Annual research review: a meta-analysis of the worldwide prevalence of mental disorders in children and adolescents. J Child Psychol Psychiatry. 2015;56(3):345-65.

36. Reid G, Stewart SL, Zaric GS, Carter JR, Neufeld RW, Tobon Jl, et al. Defining episodes of care in children's mental health using administrative data. Adm Policy Ment Health Ment Health Serv Res. 2015;42(6):737-47.

37. Saczynski JS, Andrade SE, Harrold LR, Tjia J, Cutrona SL, Dodd KS, et al. A systematic review of validated methods for identifying heart failure using administrative data. Pharmacoepidemiol Drug Saf. 2012;21:129-40.

38. Schulte-Körne G. Mental health problems in a school setting in children and adolescents. Deutsches Arzteblatt Int. 2016;113(11):183.

39. Smith JP, Smith GC. Long-term economic costs of psychological problems during childhood. Soc Sci Med. 2010;71(1):110-5.

40. Social Investment Agency. (2019). Using integrated data to understand mental health and addiction conditions. Retrieved from Wellington, New Zealand:

41. Statistics New Zealand. (2015a). IDI Data Dictionary : Programme for the integration of mental health data October 2015 edition. In.

42. Statistics New Zealand. (2015b). IDI Data Dictionary : Publicly funded hospital discharges - event and diagnosis / procedure information November 2015 edition. In.

43. Statistics New Zealand. (2015c). IDI Data Dictionary: Pharmaceutical data October 2015 edition. In

44. Statistics New Zealand. (2017a). How we keep IDI and LBD data safe. Retrieved from http://archive.stats.govt.nz/browse_for_stats/snapshots-ofnz/integrated-data-infrastructure/keep-data-safe.aspx

45. Statistics New Zealand. (2017b). Integrated Data Infrastructure. Retrieved from https://www.stats.govt.nz/integrated-data/integrated-datainfrastructure.

46. Statistics New Zealand. (2017c). Legislation, policies, and protocols. In.

47. Statistics New Zealand. (2017d). Privacy impact assessments for the IDI and LBD. Retrieved from http://archive.stats.govt.nz/browse_for_stats/snapshotsof-nz/integrated-data-infrastructure/keep-data-safe/privacy-impactassessments.aspx

48. Stewart R, Davis K. 'Big data'in mental health research: current status and emerging possibilities. Soc Psychiatry Psychiatr Epidemiol. 2016;51(8):1055-72.

49. Sung S-F, Hsieh C-Y, Lin H-J, Chen Y-W, Yang Y-HK, Li C-Y. Validation of algorithms to identify stroke risk factors in patients with acute ischemic stroke, transient ischemic attack, or intracerebral hemorrhage in an administrative claims database. Int J Cardiol. 2016;215:277-82.

50. Tu K, Campbell NR, Chen Z-L, Cauch-Dudek KJ, McAlister FA. Accuracy of administrative databases in identifying patients with hypertension. Open Med. 2007;1(1):e18.

51. World Health Organisation. (2003). Intentional self-harm Retrieved from http:// apps.who.int/classifications/apps/icd/icd10online2003/fr-icd.htm?gx60.htm

52. Zhao J, Gibb S, Jackson R, Mehta S, Exeter DJ. Constructing whole of population cohorts for health and social research using the New Zealand integrated data infrastructure. Aust N Z J Public Health. 2017:42(4):382-8.

\section{Publisher's Note}

Springer Nature remains neutral with regard to jurisdictional claims in published maps and institutional affiliations.

Ready to submit your research? Choose BMC and benefit from:

- fast, convenient online submission

- thorough peer review by experienced researchers in your field

- rapid publication on acceptance

- support for research data, including large and complex data types

- gold Open Access which fosters wider collaboration and increased citations

- maximum visibility for your research: over $100 \mathrm{M}$ website views per year

At $\mathrm{BMC}$, research is always in progress.

Learn more biomedcentral.com/submission 